\title{
A Comparative Study of Machinability of Aluminium and Its Composite with Boron Carbide by Varying Grain Size
}

\author{
Mohd Adnan \\ Department of Mechanical Engineering \\ G.R.D. Institute of Management and Technology, \\ 214 Rajpur road. Dehradun,
}

\author{
Vinod Kumar \\ Department of Mechanical Engineering \\ G.R.D. Institute of Management and Technology, \\ 214 Rajpur Road. Dehradun,
}

\begin{abstract}
Aluminum metal composite are the most encouraging material which gives most noteworthy mechanical quality in the field of hard machined material. Inferable from its higher strength to weight proportion, it is widely applied in the aeronautical assembling and aviation industries. Throughout the long term, researchers continuously practices to reduce the cost of machining process and numerous analysts have indicated unmistakable fascination for expanding further developed machining measure. During machining of aluminum compound materials, the proper machining and cooling circumstances assume a basic part as it influences the machinability. In this study, three samples are taken pure aluminium particle size 50 micron (approx), aluminium with 10\% reinforcement of boron carbide with 50 nanometer (approx). The effect of varying cutting speed and feed rate was analyzed on factors like feed force, cutting force, surface roughness and tool wear (Crater and flank wear). It was observed that at low feed rate and at high speed the machining of material was preferable.
\end{abstract}

Keywords: Boron Carbide, Matrix, MMCs, Reinforcement, AMMCs

\section{INTRODUCTION}

Aluminium silicon compounds are most appropriate for assembling automobiles parts as it decreased weight which is getting more significant both in natural and business needs. They have great corrosion resistance and reusing capacity which is a lot wanted when machining is required. Machining is pondered as one of the most basic assembling cycle to deliver parts with wanted shape and dimensional exactness. Choice of reasonable machining boundaries causes the industrialists to have command over different autonomous factors associated with machining. Numerous investigates are completed in machining measures considering cutting conditions, cutting apparatus materials, surface roughness, apparatus wear, device life, power utilization and so on.[1]

The significant advancements in science and designing is the improvement of composite materials, composites comprise of metals and their amalgams known as metal matrix composite. In Al Metal Matrix Composite (AMMC's) one constituent is aluminium combination, which go about as permeating system and is known as network stage, the other constituent is implanted in this grid stage and fill in as fortification, the support is normally non-metallic and are generally ceramics like $\mathrm{SiC}$ and $\mathrm{A} 12 \mathrm{O} 3$ by fluctuating the nature and volume portion of the constituents properties Aluminium

Metal Matrix Composites (MMC) can be custom-made. Exploration with respect to machining of metal network composite was initially started in 1980s and the majority of work depended on Aluminium Metal Matrix Composites aims on machinability uniquely tool life and the streamlining of cutting apparatus performance.[2]

Powder Metallurgy handling is a powerful strategy to fabricate MMCs with high, medium and low volume of fortification with genuinely uniform circulation. Powder metallurgy pass on to create pitifully strong (cold welding) close to the components of the item at last to be produced. Weights of $1-15$ tons are commonly used to minimal the metal powder and structure green part. At that point resulting warming or sintering is done of green part in the form with temperature underneath melting point under non oxidizing environment.[3]

\section{S. Dhanalakshmi, T. Rameshbabu. (2020)[4]}

This article examine about the enhancement of machining boundaries in turning LM 25 aluminum amalgam in wet and dry conditions. The boundaries considered for machining are cutting rate, feed and profundity of cut with the exhibition measures as surface unpleasantness, material evacuation rate and cylindricity mistake. Taguchi's L9 symmetrical exhibit was utilized for directing the examinations. The boundaries are enhanced at the same time by Gray Relational Analysis (GRA) strategy. The effect of the machining boundaries on execution measures were thought about on both wet and dry machining situations.

M. C. Santos, A. R. Machado, M. A.S. Barrozo, M. J. Jackson, E.O. Ezugwu (2014)[5] Parameters such as 
instrument wear, apparatus life, cutting temperature, machining power segments, power utilization, surface trustworthiness, and chip thickness proportion are routinely utilized. The point of this work is to examine the conduct of the machining power $(\mathrm{Fu})$, chip thickness proportion (CTR), and chip removal when turning flexible (1350-O grade) and of high quality (7075-T6 grade) aluminum composites at different cutting conditions (cutting rate: Vc, feed rate: $\mathrm{f}$, what's more, profundity of cut: doc). A central composite design (CCD) of tests was utilized that created second-request models of the boundaries: [Fu ( $\mathrm{Vc}$, doc, f); CTR (Vc, doc, f)]. Surface reaction strategies and level bends were utilized for examining the impacts of the cutting conditions on the yield boundaries: Fu also, CTR. The cutting conditions ( $\mathrm{Vc}$, doc, and f) that all the while limit the machining power $(\mathrm{Fu})$ and the CTR were resolved with the assistance of the hereditary calculation strategy (GAM).

K.K. Saravanan, S Mahendran, (2020) [6] aluminum 6082 compound is blended in with boron carbide fortified material by mechanical stirring. The example is tried by hardness and tensile test. The SEM investigations is done and compute the grain molecule conveyance. These projecting is machined in $\mathrm{CNC}$ machines. The machining boundaries speed, feed, profundity of cut and all sort of additions are considered. These machinability contemplates are contrasted and mono compound and composite materials. The machinability esteems are higher for composite material than solid combination. The oddity of this task is to examine the mechanical properties of aluminum 6082 with different weight rate of B4C materials.

\section{Ashutosh Kumar Singh, Deepak Singhal, Ramanuj} Kumar (2019)[7] work manages the machining of Aluminum 7075 with metal (brass) anode utilizing Electrical Discharge Machining Process. The impact of EDM measure boundaries on the different yield of work piece were measurably analyzed with arrangement of runs. L27 set of investigations are performed with four information sources (Pulse ON Time, Voltage Gap, Peak Current and Flushing Pressure) and their three levels. By setting the necessary boundaries, Material Removal Rate (MRR) is assessed.

And this paper deals with a comparative study of machinability of pure aluminium and aluminium metal composites at different grain size. The factors that going to be studied for machinability are cutting force, feed force and surface roughness in term of workpiece and crater and flank wear in terms of tool. All these factor are studied under different feed rate and cutting speed.

\section{MATERIAL AND METHOD}

The materials utilized in the test is Boron carbide with immaculateness $99.95 \%$, density $2.52 \mathrm{~g} / \mathrm{cm}^{\wedge} 3$ and particle size 50 micron and 50 nanometer taken from Parshwamani Metals, Mumbai. Aluminum powder with immaculateness $99.85 \%$, density $2.7 \mathrm{~g} / \mathrm{cm}^{\wedge} 3$ and particle size of 50 micron and 50 nanometer taken from Parshwamani Metals, Mumbai.

Three samples are prepared one is from pure aluminium powder of particle size 50 micron, the second sample was aluminium metal matrix composite having boron carbide as a reinforcement with weight and also the particle size of both are 50 micron, Third sample was prepared was also a Al metal matrix composite with boron carbide as reinforcement but in this sample the particle size was 50 $\mathrm{nm}$ for both aluminium and boron carbide.

For making aluminum metal network composite at first the powder is blended in with one another in weight rate as aluminum $90 \%$ and boron carbide $10 \%$ by weight for both second and third composite samples subsequent to gauging these samples are blended in stirrer for 5 hours to get homogeneous structure. And after that this blended powder are squeezed through a pneumatic press at a weight of 10 tons for 30 second and shaped green part. These green part are then send to vacuum heater for sintering where the example are heated for 60 minutes to form the composite.

As hardness of aluminium and boron carbide composites is always greater than pure aluminium.[8]-[13]. For machining cutting apparatus embed that has a piece of hard, low cover content, unalloyed WC-Co fine-grain grade, which has uses of brilliant edge wear opposition joined with high quality is utilized in the turning of aluminum and aluminium metal composites with boron carbide. A lathe machine which has a speed scope of 60$3000 \mathrm{rpm}$ was utilized for turning activities.

The machining investigations to be performed on all three samples as pure aluminium, Aluminium and boron carbide composite of both particle size 50 micron and aluminium and boron carbide composite of both particle size 50nm and their condition is appeared in Table 1 . Turning was done on the workpiece by shifting feed rates $(0.1,0.2$ and 0.3 $\mathrm{mm} / \mathrm{rev}$ ) at two diverse cutting velocities (150 and 250 $\mathrm{m} / \mathrm{min}$ ) by changing one parameter at a time

Table 1: Design of experiment for $\mathrm{Al}, \mathrm{Al} \& \mathrm{~B} 4 \mathrm{C}$ composite in micron and nanometer

\begin{tabular}{|c|c|c|c|}
\hline Sr.No. & Material & $\begin{array}{l}\text { Cutting Velocity } \\
(\mathrm{m} / \mathrm{min})\end{array}$ & $\begin{array}{ll}\begin{array}{l}\text { Feed } \\
(\mathrm{mm} / \mathrm{rev})\end{array} & \text { Rate } \\
\end{array}$ \\
\hline 1 & \multirow{6}{*}{ Pure Aluminium } & 150 & 0.1 \\
\hline 2 & & 150 & 0.2 \\
\hline 3 & & 150 & 0.3 \\
\hline 4 & & 250 & 0.1 \\
\hline 5 & & 250 & 0.2 \\
\hline 6 & & 250 & 0.3 \\
\hline 7 & \multirow{6}{*}{$\begin{array}{l}90 \% \mathrm{Al}+10 \% \mathrm{~B} 4 \mathrm{C} \\
\text { Composites (Particle } \\
\text { in micron) }\end{array}$} & 150 & 0.1 \\
\hline 8 & & 150 & 0.2 \\
\hline 9 & & 150 & 0.3 \\
\hline 10 & & 250 & 0.1 \\
\hline 11 & & 250 & 0.2 \\
\hline 12 & & 250 & 0.3 \\
\hline 13 & \multirow{6}{*}{$\begin{array}{l}90 \% \mathrm{Al}+10 \% \mathrm{~B} 4 \mathrm{C} \\
\text { Composites (Particle } \\
\text { in nanometer) }\end{array}$} & 150 & 0.1 \\
\hline 14 & & 150 & 0.2 \\
\hline 15 & & 150 & 0.3 \\
\hline 16 & & 250 & 0.1 \\
\hline 17 & & 250 & 0.2 \\
\hline 18 & & 250 & 0.3 \\
\hline
\end{tabular}


Digital microscope, surface profiler and tool dynamometer are used to analyze the change in tool wear, roughness of surface and cutting force. These three tests are done one by one in a specific order to avoid any type of error. First the cutting force has been analyzed by the help of dynamometer and the average reading has been recorded then after sample is removed from lathe and then surface roughness is measured by the help of surface profiler and at last the tool wear (flank and crater wear) has been examined by the help of optical microscope.

\section{RESULT}

\subsection{Feed force and cutting force}

The analysis is to calculate the change in cutting force by varying feed rate and velocity as shown in figure 1 and figure 2 .

The cutting force was discovered to be expanding with an expansion in feed rate in all the three samples discussed.

Figure 1: Change in Cutting Force for different feed rate at cutting speed $150 \mathrm{~m} / \mathrm{min}$.

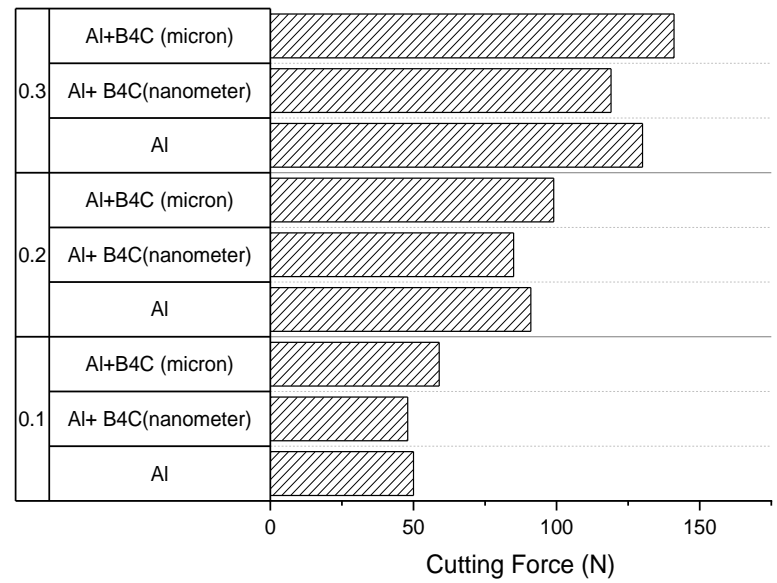

Figure 2: Change in Cutting Force for different feed rate at cutting speed $250 \mathrm{~m} / \mathrm{min}$.

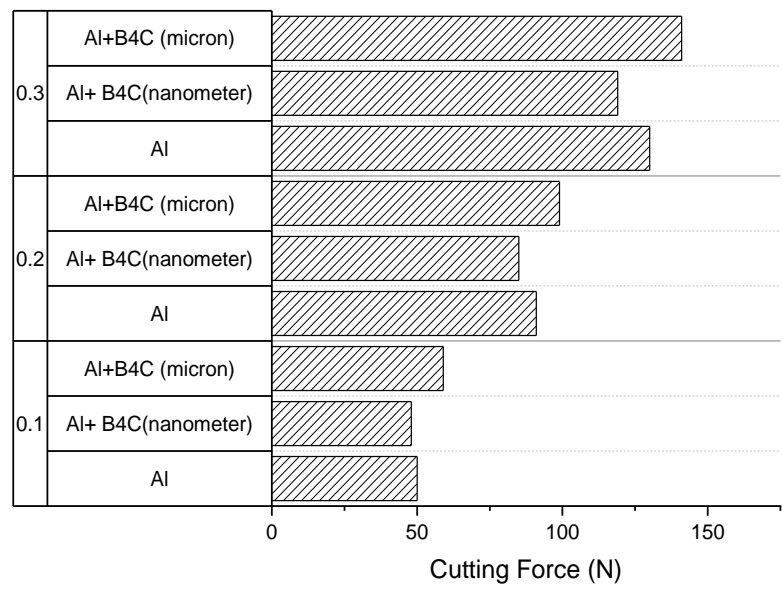

The change in cutting force with reference to cutting speed is shown in figure 3 to figure 5 for aluminium, aluminium and boron carbide of both particle size in micron and aluminium and boron carbide of both particle sizes in nanometer. It has been observed that as cutting speed is increased the value of cutting force is decreased this is because at greater speed the generation of heat is more due to that material goes to plastic state and allow easier machining. And also due to this high speed chance to form build-up edge is low and affect the generation of cutting force. So according to that machining at $250 \mathrm{~m} / \mathrm{min}$ with particle size of composite in nanometer is preferable.

Figure 3: Cutting force variation with respect to cutting speed at $0.1 \mathrm{~mm} / \mathrm{rev}$ feed rate.

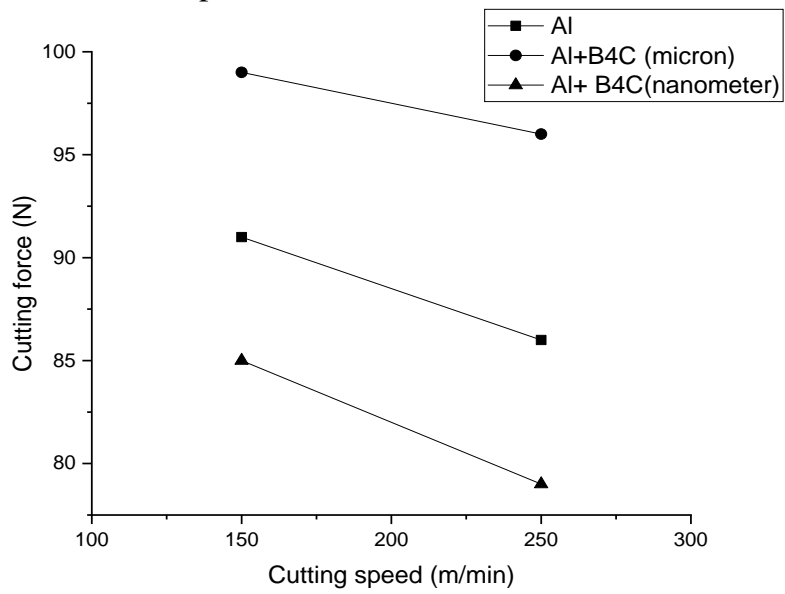

Figure 4: Cutting force variation with respect to cutting speed at $0.2 \mathrm{~mm} / \mathrm{rev}$ feed rate.

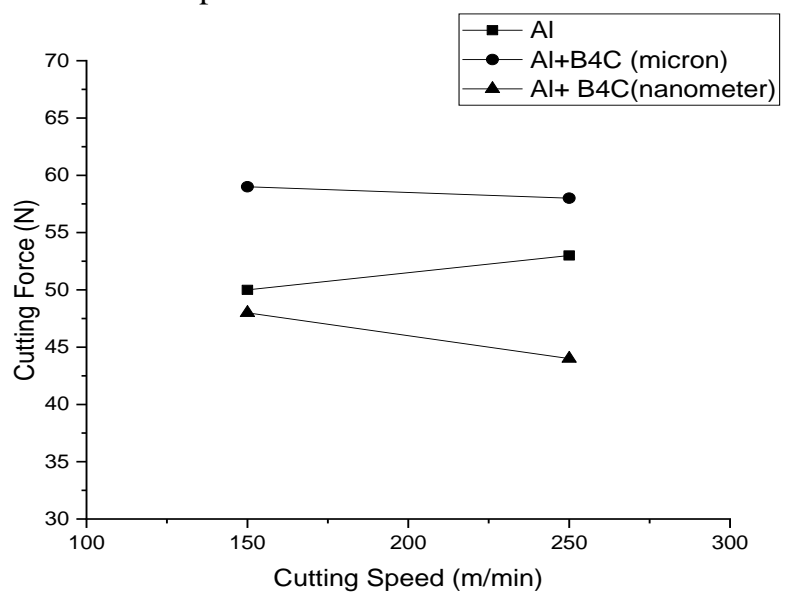

Figure 5: Cutting force variation with respect to cutting speed at $0.3 \mathrm{~mm} / \mathrm{rev}$ feed rate.

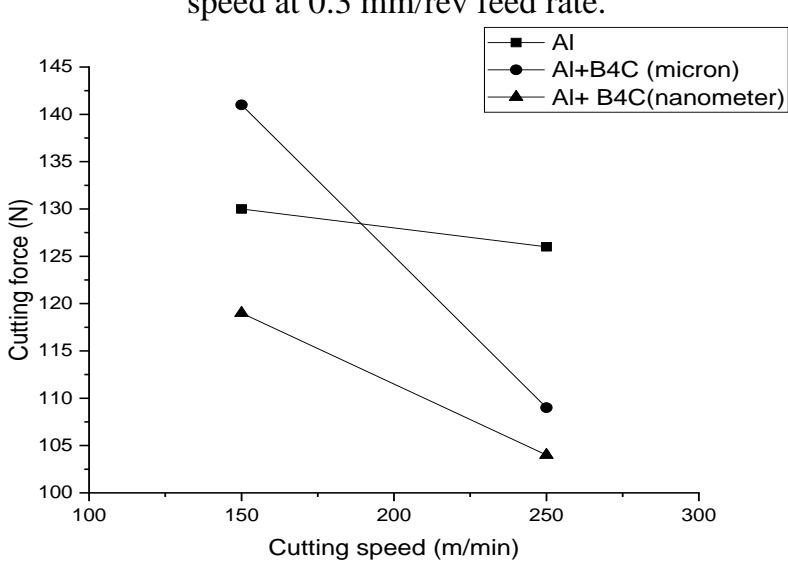

In the same manner, the effect of feed rate and cutting speed on feed force has been analyzed and shown in figure 6 and figure 7. 
Figure 6: Change in Feed Force for different feed rate at cutting speed $150 \mathrm{~m} / \mathrm{min}$.

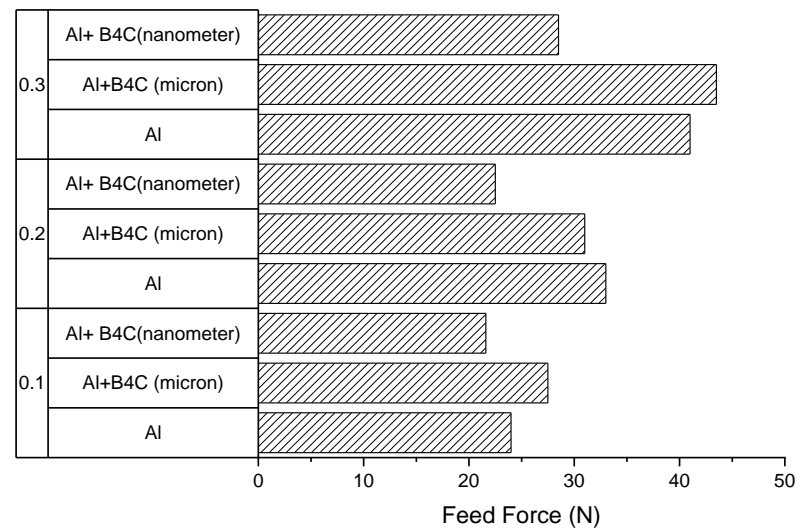

Figure 7: Change in Feed Force for different feed rate at cutting speed $250 \mathrm{~m} / \mathrm{min}$.

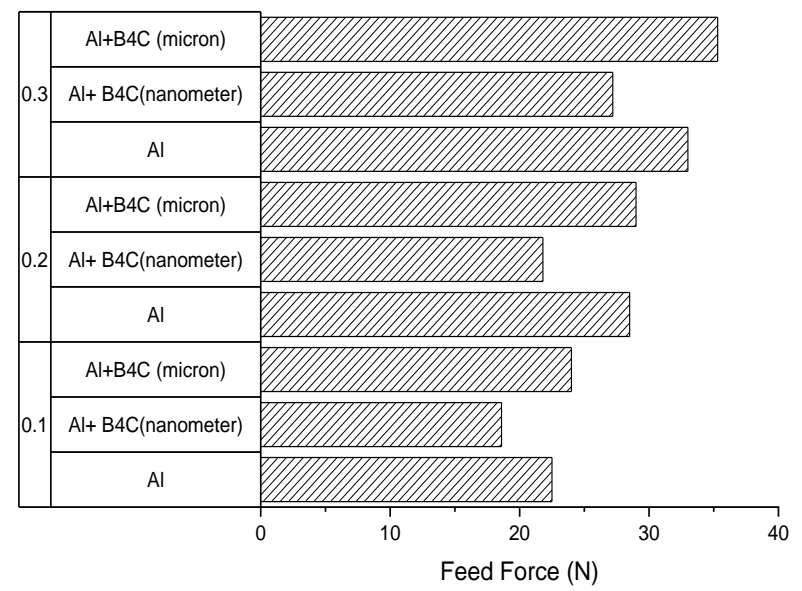

At same cutting speed if the feed rate increased there is a increment in the feed force. And on the other hand if the feed rate is constant and cutting speed enhance from $150 \mathrm{~m} / \mathrm{min}$ to $250 \mathrm{~m} / \mathrm{min}$ the required feed force is reduced this is due to the plastic behavior of material at high temperature generated because of high speed. In figure 8 to figure 10 the variation of cutting speed has been examine on feed force. So from figure 8 to figure 10 it is concluded that machining of aluminium and boron carbide composite having particle size of nanometer is most suitable at feed rate of $0.1 \mathrm{~mm} / \mathrm{min}$ and cutting speed of $250 \mathrm{~m} / \mathrm{min}$.

Figure 8: Feed force variation with respect to cutting speed at $0.1 \mathrm{~mm} / \mathrm{rev}$ feed rate.

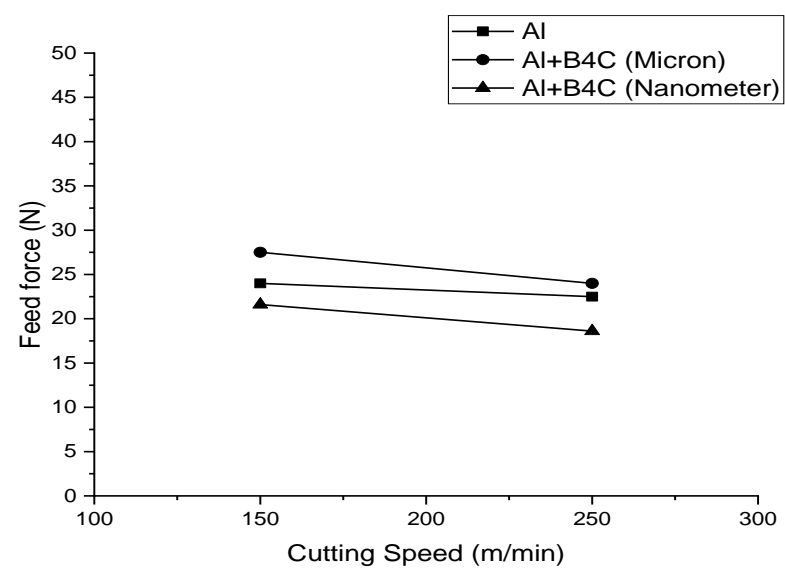

Figure 9: Feed force variation with respect to cutting speed at $0.2 \mathrm{~mm} / \mathrm{rev}$ feed rate.

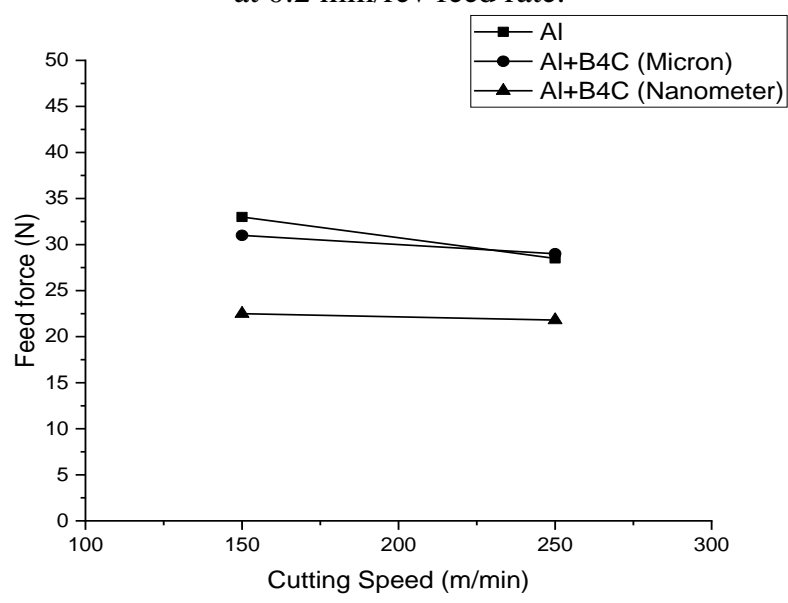

Figure 10: Feed force variation with respect to cutting speed at $0.3 \mathrm{~mm} / \mathrm{rev}$ feed rate.

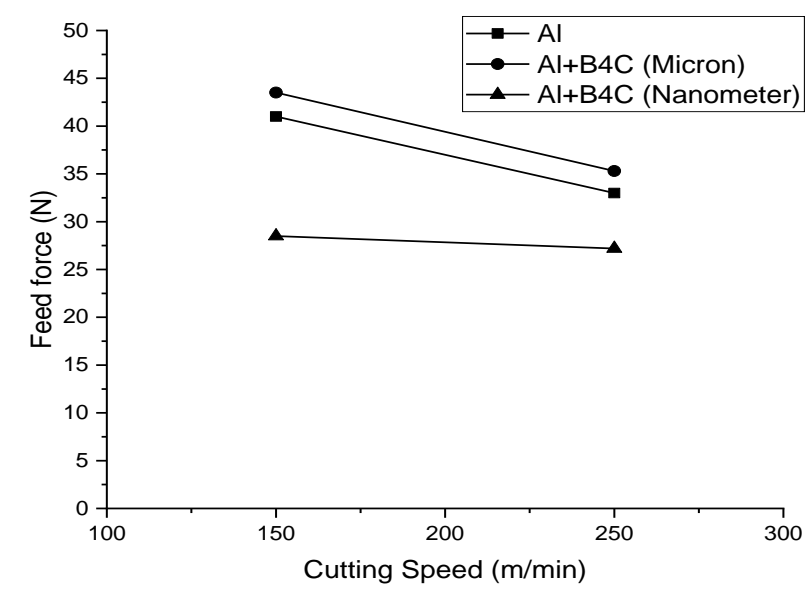

\subsection{Tool wear}

The crater wear on the instrument face and flank wear on the flank of the tool were estimated under an advanced digital microscope and the varieties were investigated. It has been observed that crater wear is always higher then flank wear. When at constant cutting speed there was an increment in feed rate both flank and crater wear were discovered to be expanding.

This is on the grounds that, with the expansion in feed, the instrument needs to eliminate an expanded volume of material in a similar stroke which enhances the tool as well as chipping temperature bringing about expanded tool wear. This is shown in figure 11, figure 12, figure 16 and figure 17. Among all the three samples aluminium, aluminium and boron carbide of both particle sizes in micron and aluminium and boron carbide of both particle sizes in nanometer the third sample of aluminium and boron carbide of particle size in nanometer show less tool wear due to small grain size. 
Figure 11: Change in Crater wear for different feed rate at cutting speed $150 \mathrm{~m} / \mathrm{min}$.

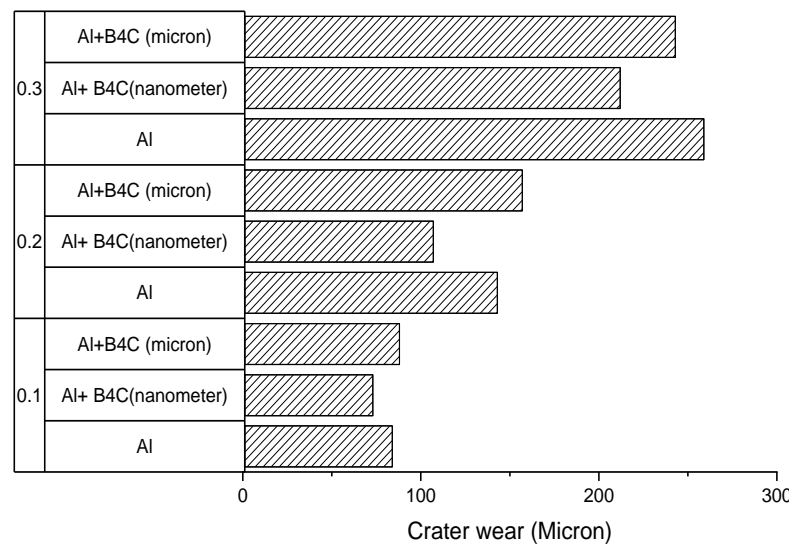

Figure 12: Change in Crater wear for different feed rate at cutting speed $250 \mathrm{~m} / \mathrm{min}$.

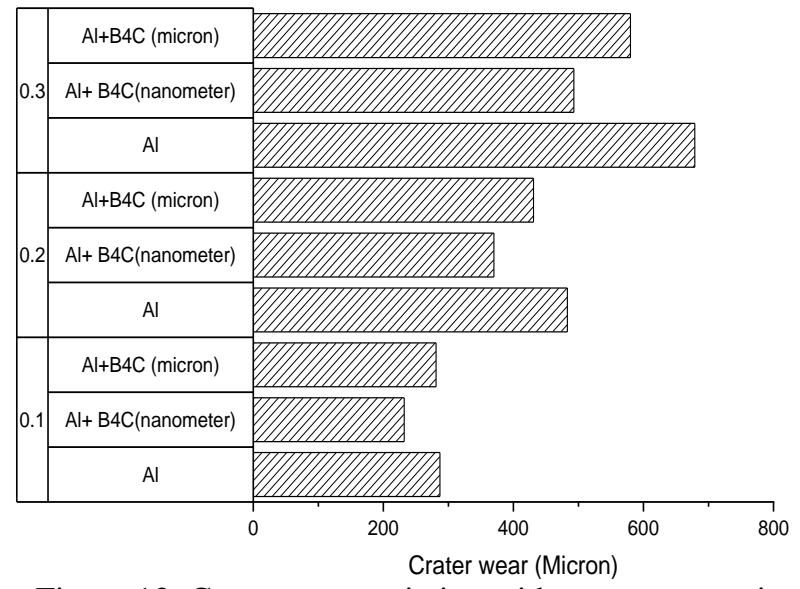

Figure 13: Crater wear variation with respect to cutting speed at $0.1 \mathrm{~mm} / \mathrm{rev}$ feed rate.

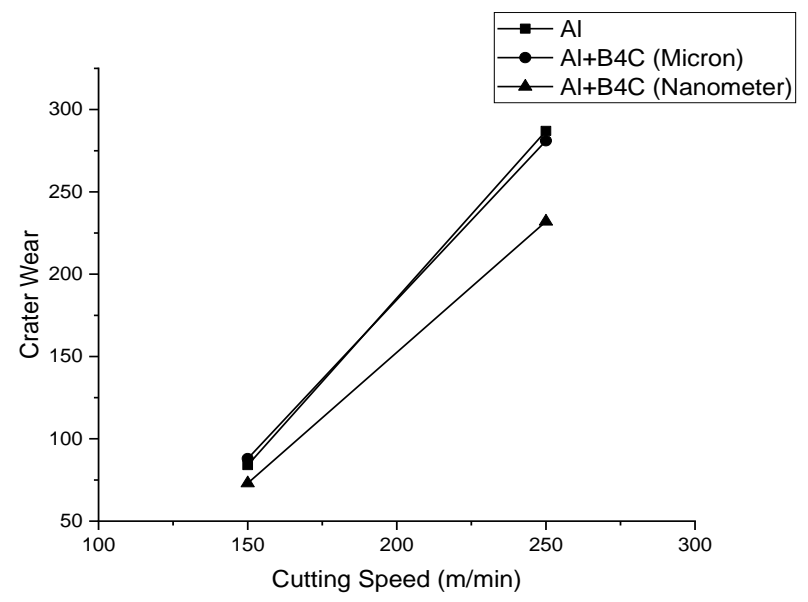

Figure 14: Crater wear variation with respect to cutting speed at $0.2 \mathrm{~mm} / \mathrm{rev}$ feed rate.

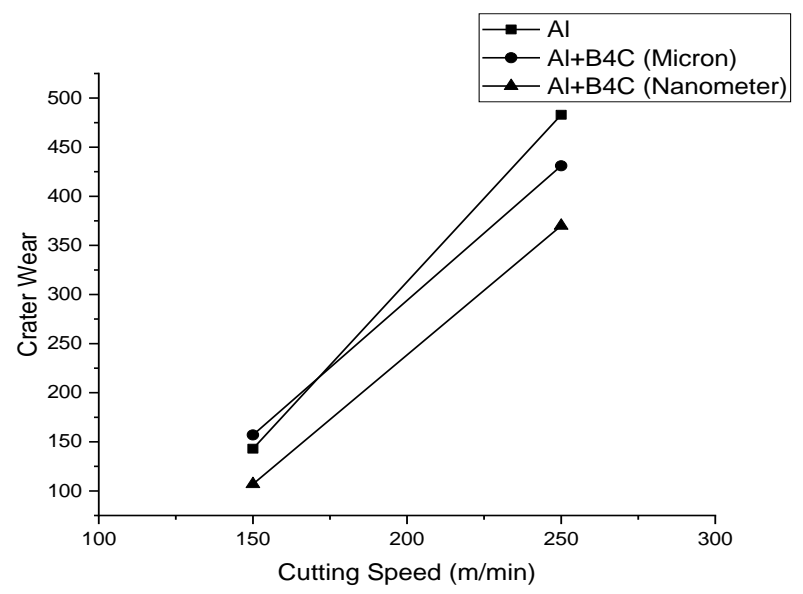

Figure 15: Crater wear variation with respect to cutting speed at $0.3 \mathrm{~mm} / \mathrm{rev}$ feed rate.

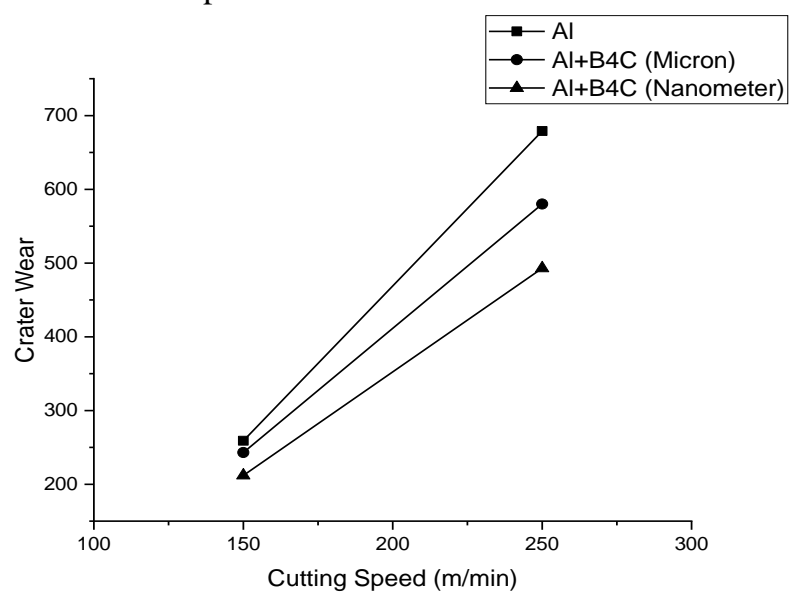

Figure 16: Change in Flank wear for different feed rate at cutting speed $150 \mathrm{~m} / \mathrm{min}$.

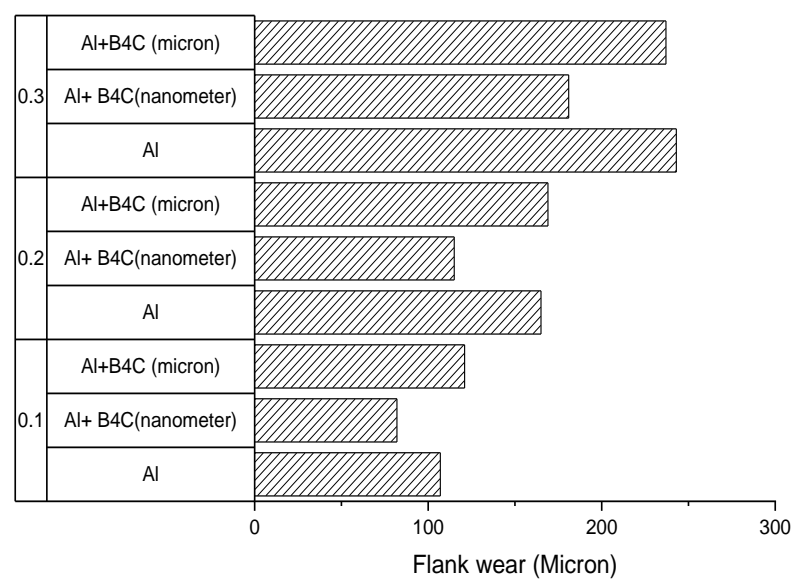


Figure 17: Change in Flank wear for different feed rate at cutting speed $250 \mathrm{~m} / \mathrm{min}$.

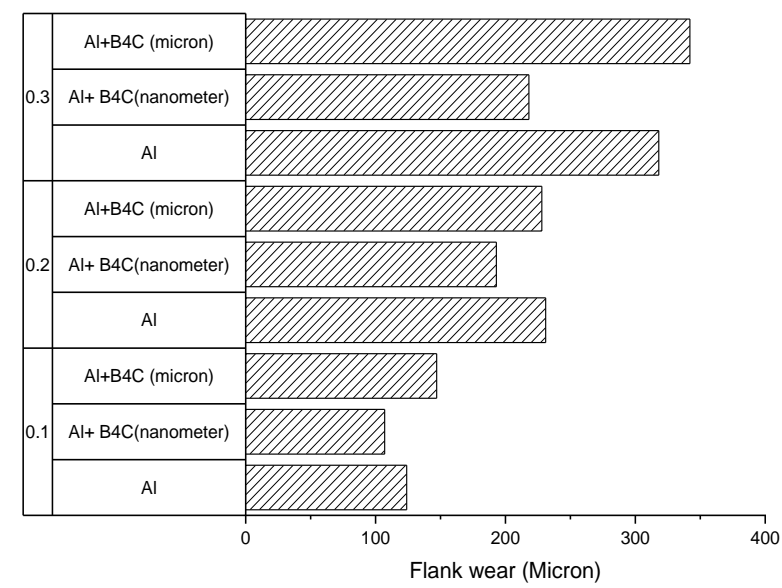

The variety of flank and crater wear concerning cutting speed at steady feed and Degree of cut are represented in Figure 13-15 and Figure 18-20. From these figures it has been observed that with an increase in feed rate the flank as well as crater wear are increased. When there is a abrasion between the workpiece and tool result is tool wear. The particle of material removed was behave like abrasion from all the samples the particle size of aluminium, aluminium and boron carbide of particle size in micron are greater in comparison of aluminium and boron carbide of particle size in nanometer due to which less resistance is offered in third sample result in less tool wear.

Figure 18: Flank wear variation with respect to cutting speed at $0.1 \mathrm{~mm} / \mathrm{rev}$ feed rate.

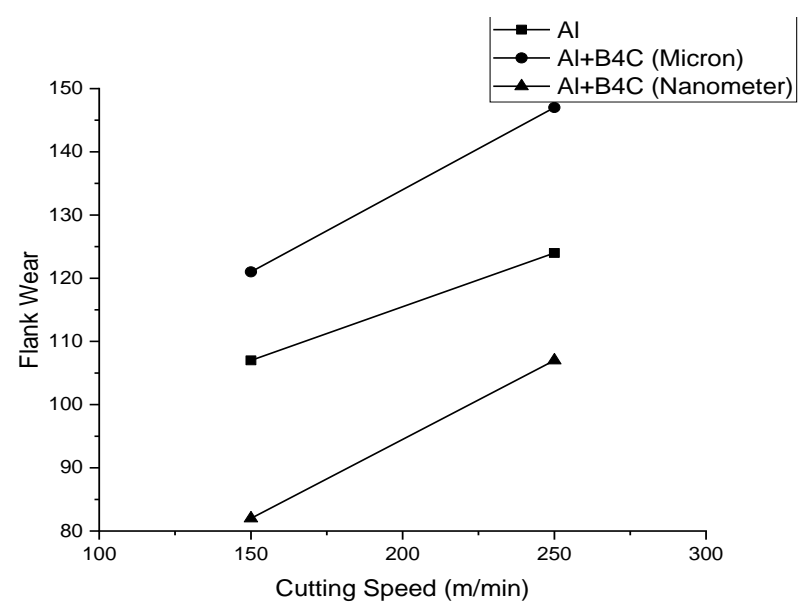

Figure 19: Flank wear variation with respect to cutting speed at $0.2 \mathrm{~mm} / \mathrm{rev}$ feed rate.

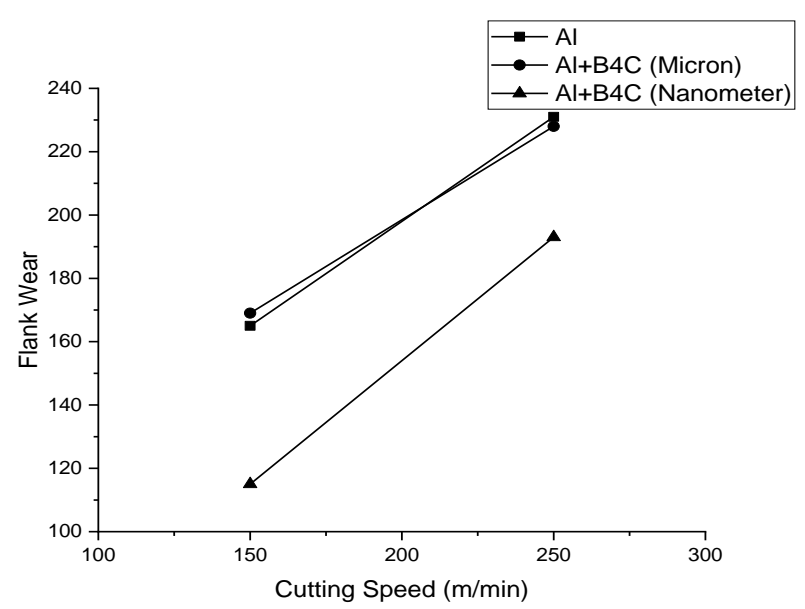

Figure 20: Flank wear variation with respect to cutting speed at $0.3 \mathrm{~mm} / \mathrm{rev}$ feed rate.

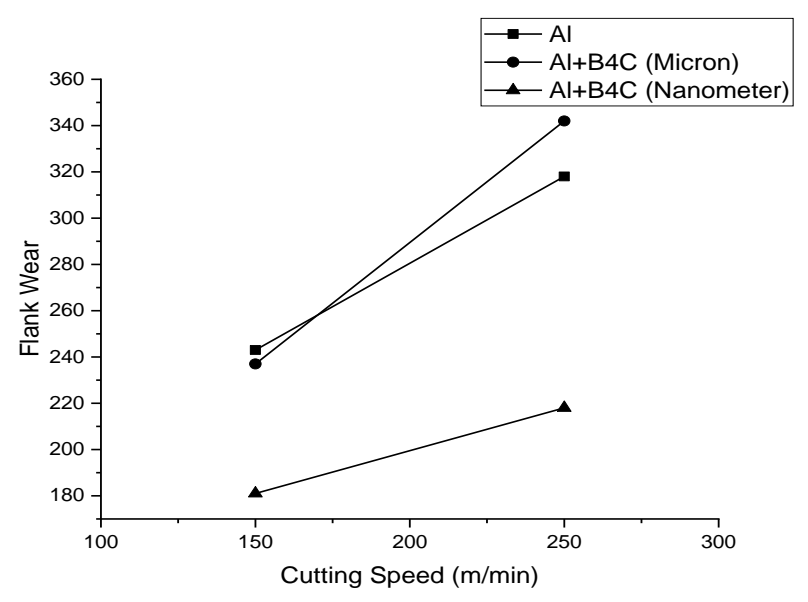

\subsection{Surface Roughness}

Figure 21 and Figure 22 are showing the effect of feed rate with different cutting speed on surface roughness. The theoretical formula used to calculate surface roughness is shown in equation 1

$\mathrm{Ra} \quad \approx \quad f r^{2} \quad /\left(n_{t}^{2} \times N^{2} \times \quad 31.2 \quad r_{n}\right)$

Where, $\mathrm{Ra}=$ mean arithmetic value of surface roughness

$f r=$ Feed rate

$\mathrm{N}=$ Cutting speed

$r_{n}=$ Nose Radius

It clearly shown for the formula that surface roughness is directly proportional to feed rate and inversely proportional to cutting speed which is justify by the practical value as shown in figure 21-22. 
Material removal rate is directly proportional to feed rate high feed rate implies high material removal which causes apparatus chipping and expands tool wear. This expansion in material expulsion additionally expands temperature and the joined impact of temperature and tool wear builds the surface roughness.

Figure 21: Change in Surface roughness for different feed rate at cutting speed $150 \mathrm{~m} / \mathrm{min}$.

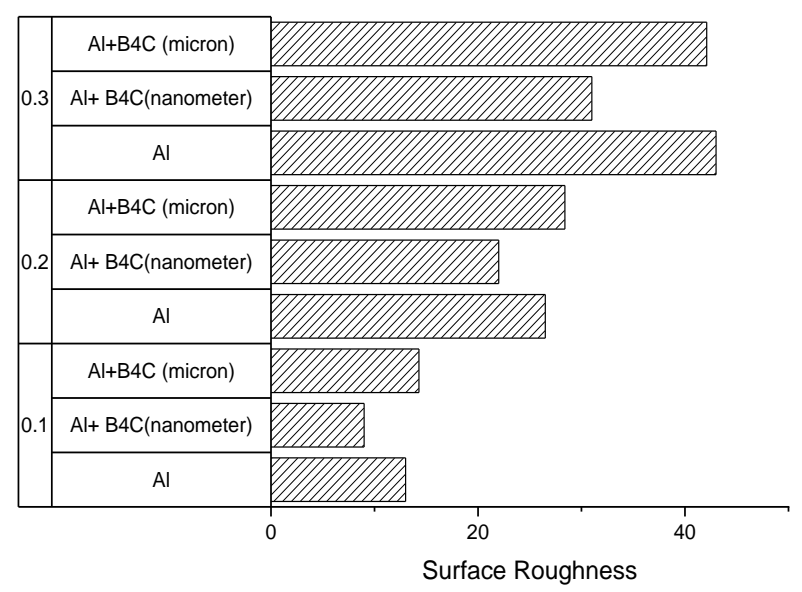

Figure 22: Change in Surface roughness for different feed rate at cutting speed $250 \mathrm{~m} / \mathrm{min}$.

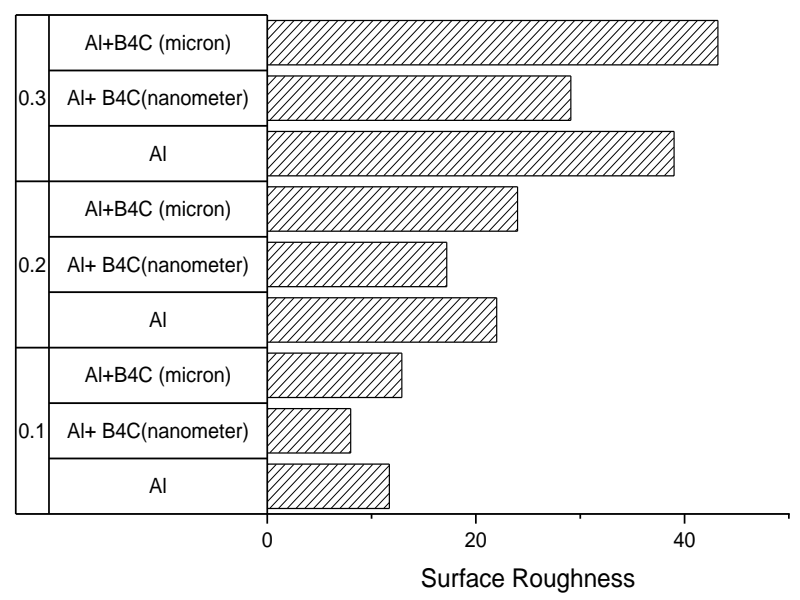

Figure 23: Surface roughness variation with respect to cutting speed at $0.1 \mathrm{~mm} / \mathrm{rev}$ feed rate.

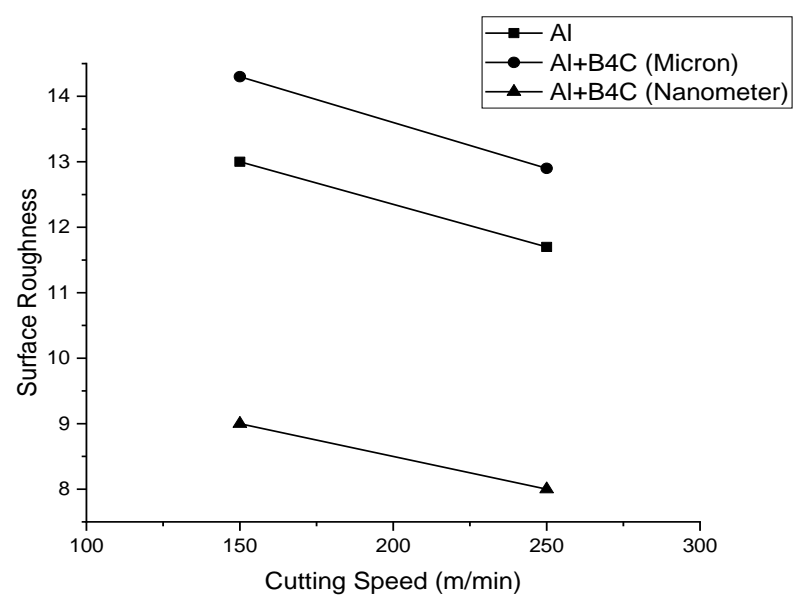

Figure 24: Surface roughness variation with respect to cutting speed at $0.2 \mathrm{~mm} / \mathrm{rev}$ feed rate.

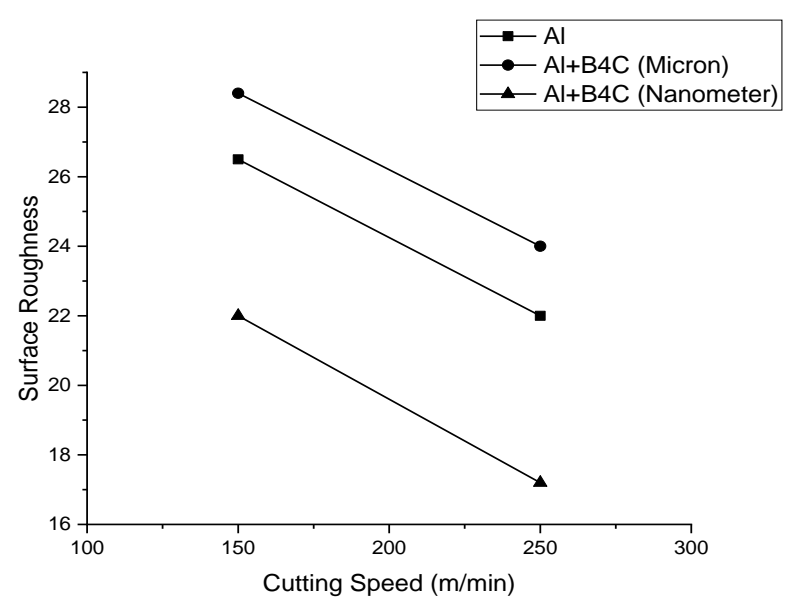

Figure 25: Surface roughness variation with respect to cutting speed at $0.3 \mathrm{~mm} / \mathrm{rev}$ feed rate.

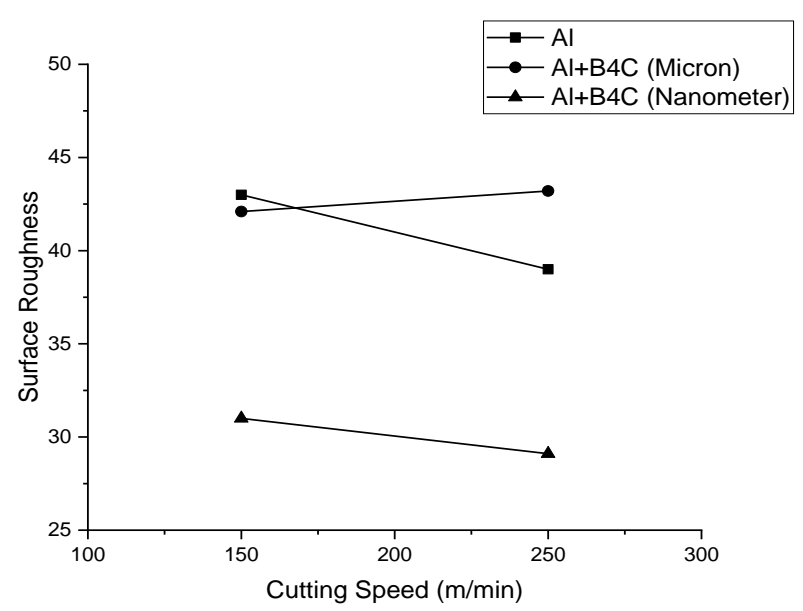

From figure 23-25 it is concluded that surface roughness is more when cutting speed is low as compared surface roughness at high speed the reason behind this was that at low cutting speed build-up edge are formed and material does not go in plastic state due to which abrasion particle increase the surface roughness while at high cutting speed more heat is generated and as a result material undergo in plastic state and there is less build-up edges are formed result in less surface roughness. Among the three samples at $250 \mathrm{~m} / \mathrm{min}$ cutting speed the surface roughness of aluminium and boron carbide composite of particle size in nanometer is least because of small grain size.

\section{CONCLUSION}

The study aims is to investigate the effect of parameters like feed rate and cutting speed on machinability factors like cutting force, feed force, tool wear and surface roughness. The result shows that at lower feed rate and at higher cutting speed the machinability was prefer. Among all three samples the machinability of $90 \%$ aluminium and $10 \%$ boron carbide by weight composite of 
particle size in nanometer is easier at $0.1 \mathrm{~mm} / \mathrm{rev}$ feed rate and $250 \mathrm{~m} / \mathrm{min}$ cutting speed. And also surface roughness of $90 \%$ aluminium and $10 \%$ boron carbide by weight composite of grain size in nanometer is less as compared pure aluminium of grain size in micron and aluminium and boron carbide composite of grain size in micron. At same composition of aluminium and boron carbide machinability effect just by varying the particle size when the particle size are in nanometer machining was easier and when the particle size are in micron machining was difficult also tool wear is more in micron size particle as compared to aluminium and boron carbide composite particle size in nanometer.

\section{REFERENCES}

[1] R. Nur, M. Y. Noordin, S. Izman, and D. Kurniawan, "Machining parameters effect in dry turning of AISI 316L stainless steel using coated carbide tools," Proc. Inst. Mech. Eng. Part E J. Process Mech. Eng., vol. 231, no. 4, pp. 676683, 2017, doi: 10.1177/0954408915624861.

[2] A. R. Bhardwaj, A. M. Vaidya, and S. P. Shekhawat, "Machining of aluminium metal matrix composite: A review," Mater. Today Proc., vol. 21, pp. 1396-1402, 2020, doi: 10.1016/j.matpr.2020.01.179.

[3] M. Jayaram, "Microstructure Analysis of Aluminium- Boron Carbide With Addition of Flyash By Using Powder Metallurgy Technique," Int. Res. J. Latest Trends Eng. Technol., vol. 2, no. 2, pp. 44-49, 2015.

[4] S. Dhanalakshmi and T. Rameshbabu, "Materials Today: Proceedings Comparative study of parametric influence on wet and dry machining of LM 25 aluminium alloy," Mater. Today Proc., no. xxxx, 2020, doi: 10.1016/j.matpr.2020.06.101.

[5] M. C. Santos, A. R. Machado, M. A. S. Barrozo, M. J. Jackson, and E. O. Ezugwu, "Multi-objective optimization of cutting conditions when turning aluminum alloys (1350-O and 7075-T6 grades) using genetic algorithm," Int. J. Adv. Manuf. Technol., vol. 76, no. 5-8, pp. 1123-1138, 2014, doi: 10.1007/s00170014-6314-5.

[6] K. K. Saravanan and S. Mahendran, "Aluminium 6082-boron carbide composite materials preparation and investigate mechanical-electrical properties with CNC turning," Mater. Today Proc., vol. 21, no. xxxx, pp. 93-97, 2020, doi: 10.1016/j.matpr.2019.05.368.

[7] A. K. Singh, D. Singhal, and R. Kumar, "Machining of aluminum 7075 alloy using EDM process: An ANN validation," Mater. Today Proc., vol. 26, no. xxxx, pp. 2839-2844, 2019, doi: 10.1016/j.matpr.2020.02.591.

[8] S. K. Tiwari, S. Soni, R. S. Rana, and A. Singh, "Effect of Heat Treatment on Mechanical Properties of Aluminium alloy-Fly ash Metal Matrix Composite," Mater. Today Proc., vol. 4, no. 2, pp. 3458-3465, 2017, doi: 10.1016/j.matpr.2017.02.235.

[9] G. Krishna, "Effect of Boron Carbide Reinforcement on Aluminium Matrix Composites," no. October, 2015.

[10] C. Nie, J. Gu, J. Liu, and D. Zhang, "Production of Boron Carbide Reinforced 2024 Aluminum Matrix Composites by Mechanical Alloying," vol. 48, no. 5, pp. 990-995, 2007, doi: 10.2320/matertrans.48.990.

[11] M. Trimurthulu, "Evaluation of Mechanical Properties of Aluminium- Boron Carbide Composites," vol. 3, no. 2, pp. 188193, 2018.

[12] M. Sankar, A. Gnanavelbabu, and K. Rajkumar, "Effect of reinforcement particles on the abrasive assisted electrochemical machining of Aluminium-Boron carbide-Graphit composite," Procedia Eng., vol. 97, pp. 381-389, 2014, doi: 10.1016/j.proeng.2014.12.262.

[13] M. Adnan, "Comparison of Mechanical Properties of Aluminium - Boron Carbide at Micron and Nanometer Size Grain Particles using Powder Metallurgy," vol. 9, no. 09, pp. 276-280, 2020. 